\title{
Brachyury, a vaccine target, is overexpressed in triple-negative breast cancer
}

\author{
Duane H Hamilton', Mario Roselli2, Patrizia Ferroni3, Leopoldo Costarelli4, \\ Francesco Cavaliere ${ }^{5}$, Mariateresa Taffuri ${ }^{4}$, Claudia Palena' ${ }^{1}$ and Fiorella Guadagni 3,6
}

'Laboratory of Tumor Immunology and Biology, Center for Cancer Research, National Cancer Institute, NIH, Bethesda, Maryland, USA

2Department of Systems Medicine, Medical Oncology, Tor Vergata Clinical Center, Tor Vergata University of Rome, Rome, Italy

${ }^{3}$ San Raffaele Roma Open University, Rome, Italy

${ }^{4}$ Department of Pathology, San Giovanni Hospital-Addolorata, Rome, Italy

5Department of Surgery, San Giovanni Hospital-Addolorata, Rome, Italy

${ }^{6}$ Interinstitutional Multidisciplinary Biobank (BioBIM), IRCCS San Raffaele Pisana, Rome, Italy

Correspondence should be addressed to C Palena

Email

palenac@mail.nih.gov

\begin{abstract}
Patients diagnosed with triple-negative breast cancer (TNBC) have a high rate of tumor metastasis and a poor prognosis. The treatment option for these patients is currently chemotherapy, which results in very low response rates. Strategies that exploit the immune system for the treatment of cancer have now shown the ability to improve survival in several tumor types. Identifying potential targets for immune therapeutic interventions is an important step in developing novel treatments for TNBC. In this study, in silico analysis of publicly available datasets and immunohistochemical analysis of primary and metastatic tumor biopsies from TNBC patients were conducted to evaluate the expression of the transcription factor brachyury, which is a driver of tumor metastasis and resistance and a target for cancer vaccine approaches. Analysis of breast cancer datasets demonstrated a predominant expression of brachyury mRNA in TNBC and in basal vs luminal or HER2 molecular breast cancer subtypes. At the protein level, variable levels of brachyury expression were detected both in primary and metastatic TNBC lesions. A strong association was observed between nuclear brachyury protein expression and the stage of disease, with nuclear brachyury being more predominant in metastatic vs primary tumors. Survival analysis also demonstrated an association between high levels of brachyury in the primary tumor and poor prognosis. Two brachyury-targeting cancer vaccines are currently undergoing clinical evaluation; the data presented here provide rationale for using brachyury-targeting immunotherapy approaches for the treatment of TNBC.
\end{abstract}
Key Words
- brachyury
- TNBC
- tumor antigen
- vaccine target

\section{Introduction}

Triple-negative breast cancer (TNBC), which accounts for approximately $10-15 \%$ of all breast tumors, is an aggressive breast cancer subtype defined through biomarker analysis by the absence of estrogen (ER) and progesterone (PR) receptor expression and lack of epidermal growth factor receptor-2 (HER2) overexpression and/or amplification. 
Due to the absence of expression of these receptors, no effective therapy is currently available for TNBC patients, which typically present a high rate of tumor relapse compared with patients with other subtypes of breast cancer (Carey et al. 2006, Haffty et al. 2006, Dent et al. 2007, O'Brien et al. 2010). With the recent use of genome-wide expression analysis, breast cancer has also been classified into various molecular subtypes. The initial classification, currently known as the 'intrinsic subtypes' and defined by the PAM50 assay, includes the luminal A, luminal B, HER2-enriched and basallike groups (Perou et al. 2000, Prat et al. 2012). Tumors of the basal-like category are usually negative for ER, PR and HER2, and thus overlap with the biomarker-defined TNBC group (Metzger-Filho et al. 2012). Several reports have now demonstrated that these tumors frequently exhibit features of tumor-initiating cells (also designated as cancer stem cells), upregulation of mesenchymal markers and downregulation of epithelial markers, thus suggesting a possible link between the phenomenon of epithelial-mesenchymal transition (EMT) and TNBC (Gupta \& Massague 2006, Sarrio et al. 2008, Jeong et al. 2012). EMT has been associated with a more invasive or metastatic tumor behavior and with the acquisition of resistance to a variety of anticancer therapies, including chemotherapy, radiation, small molecule-targeted therapies and immunotherapy (Thiery \& Sleeman 2006, Creighton et al. 2009, Kalluri \& Weinberg 2009, Huang et al. 2013, Larocca et al. 2013, Hamilton et al. 2014, David et al. 2016, Fernando et al. 2016).

Brachyury (encoded by the gene T) (Kispert et al. 1995) is a transcription factor that induces EMT in human carcinoma cells (Fernando et al. 2010) and whose expression has been reported to associate with poor prognosis in several human cancers including prostate (Pinto et al. 2014), lung (Haro et al. 2013), colon (Kilic et al. 2011) and breast (Palena et al. 2014b, Shao et al. 2015) among others. Our group has previously reported on an increased proportion of brachyury-expressing breast carcinomas negative for ER and PR (Palena et al. 2014b). However, a limited sample number precluded the evaluation of brachyury in the TNBC subgroup. In this study, the expression of brachyury was analyzed in primary and metastatic TNBC tumors using both in silico and immunohistochemical analyses. Increased frequency of samples positive for brachyury mRNA expression was observed in TNBC compared with other breast cancer subtypes. Furthermore, brachyury mRNA expression levels inversely correlated with the levels of
mRNA encoding for ER- $\alpha$ (ESR1) and PR (PGR) receptors. Immunohistochemical analysis of primary and metastatic TNBC biopsies also demonstrated variable levels of brachyury protein expression in primary and metastatic TNBC lesions. Furthermore, a strong association was observed between nuclear brachyury expression and stage of disease, with nuclear brachyury also being predominant in metastatic vs primary TNBC tumors. An association was also observed between high levels of brachyury in primary tumors and poor prognosis.

There are currently two brachyury-targeting cancer vaccines undergoing clinical evaluation (Heery et al. 2015b) (www.clinicaltrials.gov/ct2/show/NCT02179515). The data presented here provide a rationale for using brachyury-targeting immunotherapy approaches for the treatment of TNBC.

\section{Methods}

\section{Tumor cell lines}

Tumor cell lines were purchased from the American Tissue Culture Collection (ATCC), which uses STR analysis for identity verification. Cells were grown in DMEM medium (Corning) supplemented with $10 \%$ fetal bovine serum (Gemini Bio-Products), 1X antibiotic/antimycotic solution (Corning) and $4 \mu \mathrm{g} / \mathrm{mL}$ recombinant human insulin (Gibco). Cell lines were used for experiments at the following passages from purchased stocks: MDA-MB-231, passage 6; MDA-MB-436, passage 4; Hs 578T, passage 6; BT-474, passage 2; ZR-75-1, passage 4; and MCF7, passage 1.

\section{Patients and tissue collection}

Seventy-seven patients with histologically diagnosed primary TNBC and ten patients with metastatic TNBC were enrolled in the Inter-Institutional Multidisciplinary BioBank of the Biomarker Discovery and Advanced Technologies (BioDAT) Laboratory, IRCCS San Raffaele Pisana, Rome, Italy. In collaboration with the Surgical and Pathology Departments of San Giovanni Addolorata Hospital and the Medical Oncology Unit of the 'Tor Vergata' Clinical Center, Rome, Italy, primary breast and metastatic tumor tissue samples were collected at the time of surgery. Patient characteristics are provided in Table 1. Clinical follow-up data were available from 58 of 77 patients with primary TNBC. Patients received the following treatment regimens: 30 of 58 received anthracycline-based therapy; 4 of 58 received 
Table 1 Patient characteristics.

\begin{tabular}{|c|c|c|}
\hline & $\begin{array}{c}\text { Overall population } \\
(n=87)\end{array}$ & $\begin{array}{l}\text { Follow-up population } \\
\qquad(n=58)\end{array}$ \\
\hline \multicolumn{3}{|l|}{$\begin{array}{l}\text { Primary breast } \\
\text { cancer }(n=77)\end{array}$} \\
\hline $\begin{array}{l}\text { Age, year } \\
(\text { Mean } \pm \text { S.D.) }\end{array}$ & $63 \pm 16$ & $63 \pm 16$ \\
\hline \multicolumn{3}{|l|}{ Menopausal status } \\
\hline Pre & $27(35 \%)$ & $21(36 \%)$ \\
\hline Post & $50(65 \%)$ & $37(64 \%)$ \\
\hline \multicolumn{3}{|l|}{$\begin{array}{l}\text { Pathological } \\
\text { diagnosis }\end{array}$} \\
\hline $\begin{array}{l}\text { Infiltrating ductal } \\
\text { carcinoma }\end{array}$ & $70(91 \%)$ & $54(93 \%)$ \\
\hline $\begin{array}{l}\text { Infiltrating lobular } \\
\text { carcinoma }\end{array}$ & $5(6 \%)$ & $2(3.5 \%)$ \\
\hline Othersa & $2(3 \%)$ & $2(3.5 \%)$ \\
\hline \multicolumn{3}{|l|}{ Grading } \\
\hline 1 & $0(0 \%)$ & $0(0 \%)$ \\
\hline 2 & $0(0 \%)$ & $0(0 \%)$ \\
\hline 3 & $77(100 \%)$ & $58(100 \%)$ \\
\hline \multicolumn{3}{|l|}{ Stage } \\
\hline I & $28(36 \%)$ & $21(36 \%)$ \\
\hline II & $27(35 \%)$ & $24(42 \%)$ \\
\hline III & $20(26 \%)$ & $13(22 \%)$ \\
\hline IV & $2(3 \%)$ & $0(0 \%)$ \\
\hline \multicolumn{3}{|l|}{ p53 expression } \\
\hline Negative & $41(53 \%)$ & $26(45 \%)$ \\
\hline Positive & $36(47 \%)$ & $32(55 \%)$ \\
\hline \multicolumn{3}{|l|}{ Ki67 expression } \\
\hline Median (range) & $70(40-90)$ & $56(40-90)$ \\
\hline Positive, $n(\%)^{b}$ & $76(99 \%)$ & $57(98 \%)$ \\
\hline \multicolumn{3}{|l|}{$\begin{array}{l}\text { Metastatic breast } \\
\text { cancer }(n=10)\end{array}$} \\
\hline $\begin{array}{l}\text { Age, year } \\
(\text { Mean } \pm \text { S.D.) }\end{array}$ & $63 \pm 17$ & \\
\hline \multicolumn{3}{|l|}{ Menopausal status } \\
\hline Pre & $4(40 \%)$ & \\
\hline Post & $6(60 \%)$ & \\
\hline \multicolumn{3}{|l|}{$\begin{array}{l}\text { Pathological } \\
\text { diagnosis }\end{array}$} \\
\hline $\begin{array}{l}\text { Infiltrating ductal } \\
\text { carcinoma }\end{array}$ & $9(90 \%)$ & \\
\hline $\begin{array}{l}\text { Infiltrating lobular } \\
\text { carcinoma }\end{array}$ & $1(10 \%)$ & \\
\hline \multicolumn{3}{|l|}{ p53 expression } \\
\hline Negative & $8(80 \%)$ & \\
\hline Positive & $2(20 \%)$ & \\
\hline \multicolumn{3}{|l|}{ Ki67 expression } \\
\hline Median (range) & $63(50-80)$ & \\
\hline Positive, $n(\%)^{\mathrm{b}}$ & $9(90 \%)$ & \\
\hline
\end{tabular}

ancludes a case of comedocarcinoma and a metaplastic breast cancer; bKi67 positivity defined as $\geq 20$.

non-anthracycline-based regimens (CMF); 5 of 58 received adjuvant radiotherapy alone; 8 of 58 did not receive treatment and treatment data were not available for the remaining 11 of 58 patients. Informed consent was obtained from each participating subject. The study was performed under the appropriate institutional ethics approval and in accordance with the principles embodied in the Declaration of Helsinki.

\section{Immunohistochemical detection of brachyury}

Sections of formalin-fixed, paraffin-embedded tissues were evaluated for brachyury expression by using a rabbit monoclonal anti-brachyury antibody (MAb 54-1) at a 1:500 dilution (Hamilton et al. 2015). Staining was performed on the Ventana BenchMark XT automated staining platform with the UltraView Universal DAB Detection Kit (Roche) according to manufacturer's instructions. Two pathologists independently evaluated the tumor and normal tissue samples in a blinded, randomized manner. For each slide, three to five random fields were evaluated; for each field, the percentage of positive tumor cells was calculated as: ((number of positive tumor cells/total number of tumor cells) $\times 100$ ). Nuclear, cytoplasmic and total brachyury staining was independently scored, with brachyury being observed either in the nucleus, the cytosol or both compartments of the tumor cells. For calculation of total brachyury expression (Table 2), the percentage of tumor cells with mutually exclusive cytosolic or nuclear staining was added. Tumor cells showing brachyury in both compartments were scored only once. The relative staining intensity was scored as weak (+) for pale brown intensity, moderate $(++)$ for intermediate brown intensity and strong (+++) for intense, dark brown immunoprecipitate. Immunoreactivity index was calculated by multiplying the percentage of positive cells by the staining intensity. For normal tissues, the percentage of reactivity was individually evaluated for each cell type and calculated as: ((number of positive cells/total number of cells of the same type $) \times 100$ ).

\section{In silico analysis of the TCGA dataset}

Relative expression levels of indicated mRNAs were assessed using the TCGA dataset containing data from 1026 breast carcinoma patients (http://cancergenome. nih.gov). For the analysis, breast cancer samples were subdivided into three groups according to the level of brachyury (T) expression: 881 of 1026 samples with no detectable brachyury expression were classified as negative (neg). The remaining 145 samples were ranked and subdivided into 'brachyury-high' (high, 73 of 1026) and 'brachyury-low' (low, 72 of 1026) groups based on an arbitrary cutoff set at the median value for the 145 samples. The level of expression of mRNA encoding

Published by Bioscientifica Ltd 
Table 2 Immunohistochemical detection of brachyury in biopsies obtained from primary lesions of TNBC patients.

\begin{tabular}{|c|c|c|c|c|c|c|c|c|c|c|c|c|}
\hline \multirow[b]{2}{*}{$\mathrm{Pt}$} & \multirow[b]{2}{*}{ Stage } & \multirow[b]{2}{*}{ Ki67 } & \multirow[b]{2}{*}{ p53 } & \multicolumn{3}{|c|}{ Nuclear brachyury } & \multicolumn{3}{|c|}{ Cytoplasmic brachyury } & \multicolumn{3}{|c|}{ Total brachyury } \\
\hline & & & & Pos (\%) & SI & Index & Pos $(\%)$ & $\mathrm{SI}$ & Index & Pos $(\%)$ & SI & Index \\
\hline 1 & 1 & 90 & NEG & 100 & +++ & 300 & 70 & ++ & 140 & 100 & +++ & 300 \\
\hline 2 & I & 25 & POS & 100 & +++ & 300 & 100 & ++ & 200 & 100 & +++ & 300 \\
\hline 3 & i & 35 & POS & 70 & +++ & 210 & 100 & ++ & 200 & 100 & +++ & 300 \\
\hline 4 & 1 & 60 & POS & 60 & +++ & 180 & 80 & ++ & 160 & 90 & +++ & 270 \\
\hline 5 & I & 80 & NEG & 90 & +++ & 270 & 10 & + & 10 & 90 & +++ & 270 \\
\hline 6 & I & 60 & NEG & 20 & ++ & 40 & 80 & +++ & 240 & 80 & +++ & 240 \\
\hline 7 & 1 & 80 & NEG & 80 & ++ & 160 & 50 & + & 50 & 80 & ++ & 160 \\
\hline 8 & I & 90 & POS & 20 & + & 20 & 80 & + & 80 & 80 & + & 80 \\
\hline 9 & I & 90 & POS & 30 & + & 30 & 80 & ++ & 160 & 80 & ++ & 160 \\
\hline 10 & 1 & 40 & NEG & 70 & ++ & 140 & 10 & + & 10 & 70 & ++ & 140 \\
\hline 11 & 1 & 70 & POS & 50 & +++ & 150 & 70 & + & 70 & 70 & +++ & 210 \\
\hline 12 & I & 20 & POS & 40 & +++ & 120 & 60 & ++ & 120 & 70 & +++ & 210 \\
\hline 13 & I & 70 & NEG & 20 & + & 20 & 70 & ++ & 140 & 70 & ++ & 140 \\
\hline 14 & 1 & 20 & NEG & 70 & +++ & 210 & 70 & + & 70 & 70 & +++ & 210 \\
\hline 15 & $i$ & 35 & POS & 60 & +++ & 180 & 20 & + & 20 & 60 & +++ & 180 \\
\hline 16 & I & 40 & POS & 60 & ++ & 120 & 40 & + & 40 & 60 & ++ & 120 \\
\hline 17 & 1 & 60 & POS & 20 & + & 20 & 50 & + & 50 & 50 & + & 50 \\
\hline 18 & $i$ & 80 & NEG & 20 & ++ & 40 & 50 & + & 50 & 50 & ++ & 100 \\
\hline 19 & I & 90 & POS & 40 & ++ & 80 & 40 & + & 40 & 40 & ++ & 80 \\
\hline 20 & 1 & 50 & NEG & 40 & ++ & 80 & 10 & + & 10 & 40 & ++ & 80 \\
\hline 21 & 1 & 25 & NEG & 10 & + & 10 & 40 & + & 40 & 40 & + & 40 \\
\hline 22 & I & 40 & NEG & 25 & ++ & 50 & 10 & + & 10 & 30 & + & 60 \\
\hline 23 & I & 40 & NEG & 15 & ++ & 30 & 20 & + & 20 & 25 & + & 50 \\
\hline 24 & 1 & 70 & POS & 15 & + & 15 & 15 & + & 15 & 20 & + & 20 \\
\hline 25 & 1 & 80 & POS & 20 & + & 20 & 10 & + & 10 & 20 & + & 20 \\
\hline 26 & 1 & 40 & POS & 20 & ++ & 40 & 0 & - & 0 & 20 & ++ & 40 \\
\hline 27 & 1 & 70 & NEG & 10 & ++ & 20 & 10 & + & 10 & 15 & ++ & 30 \\
\hline 28 & $i$ & 90 & POS & 0 & - & 0 & 0 & - & 0 & 0 & - & 0 \\
\hline 29 & IIA & 25 & POS & 100 & ++ & 200 & 10 & + & 10 & 100 & ++ & 200 \\
\hline 30 & $\| A$ & 90 & POS & 80 & +++ & 240 & 80 & ++ & 160 & 100 & +++ & 300 \\
\hline 31 & IIA & 60 & POS & 20 & +++ & 60 & 100 & ++ & 200 & 100 & +++ & 300 \\
\hline 32 & IIA & 90 & POS & 80 & +++ & 240 & 100 & +++ & 300 & 100 & +++ & 300 \\
\hline 33 & $\| A$ & 40 & POS & 100 & +++ & 300 & 10 & ++ & 20 & 100 & +++ & 300 \\
\hline 34 & $\| A$ & 45 & POS & 30 & + & 30 & 100 & ++ & 200 & 100 & ++ & 200 \\
\hline 35 & IIA & 85 & POS & 90 & +++ & 270 & 20 & + & 20 & 90 & +++ & 270 \\
\hline 36 & IIA & 90 & POS & 80 & +++ & 240 & 60 & + & 60 & 90 & +++ & 270 \\
\hline 37 & $\| A$ & 90 & NEG & 70 & +++ & 210 & 80 & + & 80 & 80 & +++ & 240 \\
\hline 38 & IIA & 25 & NEG & 80 & +++ & 240 & 10 & + & 10 & 80 & +++ & 240 \\
\hline 39 & IIA & 70 & POS & 30 & ++ & 60 & 80 & + & 80 & 80 & ++ & 160 \\
\hline 40 & $\| A$ & 40 & POS & 80 & ++ & 160 & 50 & ++ & 100 & 80 & ++ & 160 \\
\hline 41 & $\| A$ & 90 & NEG & 70 & +++ & 210 & 20 & ++ & 40 & 70 & +++ & 210 \\
\hline 42 & $\| A$ & 35 & POS & 50 & ++ & 100 & 30 & + & 30 & 50 & ++ & 100 \\
\hline 43 & $\| A$ & 60 & NEG & 25 & ++ & 50 & 10 & + & 10 & 30 & ++ & 60 \\
\hline 44 & $\| A$ & 70 & POS & 10 & + & 10 & 0 & - & 0 & 10 & + & 10 \\
\hline 45 & IIA & 60 & POS & 10 & + & 10 & 0 & - & 0 & 10 & + & 10 \\
\hline 46 & $\| A$ & 90 & NEG & 10 & + & 10 & 0 & - & 0 & 10 & + & 10 \\
\hline 47 & $\| A$ & 25 & NEG & 5 & + & 5 & 0 & - & 0 & 5 & + & 5 \\
\hline 48 & IIB & 35 & POS & 75 & ++ & 150 & 100 & + & 100 & 100 & ++ & 200 \\
\hline 49 & IIB & 20 & POS & 20 & ++ & 40 & 80 & + & 80 & 80 & + & 160 \\
\hline 50 & IIB & 60 & NEG & 40 & +++ & 120 & 70 & ++ & 140 & 70 & +++ & 210 \\
\hline 51 & IIB & 80 & NEG & 70 & +++ & 210 & 30 & + & 30 & 70 & +++ & 210 \\
\hline 52 & IIB & 90 & NEG & 50 & ++ & 100 & 50 & + & 50 & 60 & ++ & 120 \\
\hline 53 & IIB & 80 & NEG & 60 & ++ & 120 & 20 & + & 20 & 60 & ++ & 120 \\
\hline 54 & IIB & 90 & POS & 30 & +++ & 90 & 20 & ++ & 40 & 40 & +++ & 120 \\
\hline 55 & IIB & 90 & NEG & 30 & + & 30 & 30 & + & 30 & 30 & + & 30 \\
\hline 56 & IIIA & 90 & POS & 80 & +++ & 240 & 100 & + & 100 & 100 & +++ & 300 \\
\hline
\end{tabular}

(Continued) 
Table 2 Continued.

\begin{tabular}{|c|c|c|c|c|c|c|}
\hline \multirow[b]{2}{*}{ Pt } & \multirow[b]{2}{*}{ Stage } & \multirow[b]{2}{*}{ Ki67 } & \multirow[b]{2}{*}{ p53 } & \multicolumn{3}{|c|}{ Nuclear brachyury } \\
\hline & & & & Pos $(\%)$ & SI & Index \\
\hline 57 & IIIA & 90 & NEG & 100 & +++ & 300 \\
\hline 58 & IIIA & 10 & NEG & 90 & +++ & 270 \\
\hline 59 & IIIA & 30 & NEG & 90 & + & 90 \\
\hline 60 & IIIA & 60 & NEG & 80 & ++ & 160 \\
\hline 61 & IIIA & 80 & NEG & 70 & +++ & 210 \\
\hline 62 & IIIA & 70 & NEG & 70 & +++ & 210 \\
\hline 63 & IIIA & 70 & NEG & 40 & + & 40 \\
\hline 64 & IIIA & 50 & NEG & 50 & ++ & 100 \\
\hline 65 & IIIA & 60 & NEG & 40 & + & 40 \\
\hline 66 & IIIB & 95 & POS & 40 & +++ & 120 \\
\hline 67 & IIIB & 35 & NEG & 100 & +++ & 300 \\
\hline 68 & IIIB & 70 & NEG & 100 & +++ & 300 \\
\hline 69 & IIIB & 80 & NEG & 100 & +++ & 300 \\
\hline 70 & IIIB & 80 & NEG & 90 & +++ & 270 \\
\hline 71 & IIIB & 40 & POS & 80 & +++ & 240 \\
\hline 72 & IIIB & 50 & POS & 60 & ++ & 120 \\
\hline 73 & IIIB & 80 & NEG & 70 & ++ & 210 \\
\hline 74 & IIIB & 90 & NEG & 50 & +++ & 150 \\
\hline 75 & IIIB & 90 & POS & 30 & + & 30 \\
\hline 76 & IV & 90 & NEG & 30 & ++ & 60 \\
\hline 77 & IV & 80 & NEG & 15 & +++ & 45 \\
\hline
\end{tabular}

\begin{tabular}{|c|c|c|}
\hline \multicolumn{3}{|c|}{ Cytoplasmic brachyury } \\
\hline Pos (\%) & SI & Index \\
\hline 0 & - & 0 \\
\hline 50 & ++ & 100 \\
\hline 30 & + & 30 \\
\hline 60 & ++ & 120 \\
\hline 60 & + & 60 \\
\hline 10 & + & 10 \\
\hline 60 & + & 60 \\
\hline 10 & + & 10 \\
\hline 15 & + & 15 \\
\hline 100 & + & 100 \\
\hline 50 & ++ & 100 \\
\hline 30 & + & 30 \\
\hline 10 & + & 10 \\
\hline 20 & + & 20 \\
\hline 40 & + & 40 \\
\hline 60 & ++ & 120 \\
\hline 70 & + & 70 \\
\hline 50 & + & 50 \\
\hline 30 & + & 30 \\
\hline 40 & + & 40 \\
\hline 10 & + & 10 \\
\hline
\end{tabular}

\begin{tabular}{|c|c|c|}
\hline \multicolumn{3}{|c|}{ Total brachyury } \\
\hline Pos (\%) & SI & Index \\
\hline 100 & +++ & 300 \\
\hline 90 & +++ & 270 \\
\hline 90 & + & 90 \\
\hline 90 & ++ & 180 \\
\hline 80 & +++ & 240 \\
\hline 70 & +++ & 210 \\
\hline 60 & + & 60 \\
\hline 50 & ++ & 100 \\
\hline 45 & + & 45 \\
\hline 100 & ++ & 200 \\
\hline 100 & +++ & 300 \\
\hline 100 & ++ & 200 \\
\hline 100 & +++ & 300 \\
\hline 90 & +++ & 270 \\
\hline 80 & +++ & 240 \\
\hline 80 & ++ & 160 \\
\hline 80 & +++ & 240 \\
\hline 50 & +++ & 150 \\
\hline 40 & + & 40 \\
\hline 50 & ++ & 100 \\
\hline 10 & +++ & 30 \\
\hline
\end{tabular}

NEG, negative; POS, positive; SI, staining intensity.

ER- $\alpha$ (ESR1), ER- $\beta$ (ESR2), PR (PGR) and HER2 (ERBB2) were evaluated in each group. A subset of tumors in the database $(n=513)$ for which data were available regarding the four intrinsic subtypes using the PAM50 discriminator assay (Parker et al. 2009) was further assessed for brachyury expression (Cancer Genome Atlas Network 2012). Samples were also subdivided into subgroups according to ER, PR and HER2 status for comparison of the levels of mRNAs encoding for brachyury, various EMT transcription factors and the chemokine IL8. Samples were classified as triple positive (ER+, PR+ and HER2+), TNBC (ER-, PR- and HER2-) and non-TNBC. Non-TNBC corresponds to tumors that were at least positive for one marker (ER, PR or HER2). All data were analyzed using the Nexus Expression 3 analysis software package (BioDiscovery).

\section{Immunofluorescence}

Tumor cells were cultured in 96-well black, clearbottom plates (Greiner Bio-One). After fixation with 3\% paraformaldehyde (Electron Microscopy sciences), permeabilization with $0.05 \%$ Triton $\mathrm{X}$ and blockade by 1X PBS supplemented with 1\% BSA and 10\% goat serum, cells were stained using antibodies reactive against vimentin (Dako), fibronectin, ZO1 (BD Biosciences, San Jose, CA, USA), and brachyury (MAb 54-1) and Alexa Fluor 488 anti-mouse or anti-rabbit secondary antibodies. Nuclei were stained using DAPI (Thermo Fisher Scientific), and images were acquired using a Celigo S Cell Imaging Cytometer (Nexcelom Bioscience, Lawrence, MA, USA). To silence brachyury expression, control and brachyurytargeting ON-TARGETplus SMARTpool siRNAs were purchased from Dharmacon and used according to the manufacturer's instructions (GE Life Sciences, Pittsburgh, PA, USA). Cells were incubated for $72 \mathrm{~h}$ in an antibioticfree medium before it is used in the analysis of various markers by immunofluorescence.

\section{Quantitative real-time PCR}

Total RNA was prepared using the PureLink RNA Mini Kit (Thermo Fisher Scientific) and reverse-transcribed with the XLAScript cDNA MasterMix (WordWide Life Sciences). The resulting cDNA (10 ng) was amplified in triplicate with the following TaqMan human gene expression assays (Life Technologies): T (brachyury) (Hs00610080_m1) and GAPDH (4326317E) using a 7300 Applied Biosystems instrument. Expression of brachyury relative to GAPDH was calculated as $2^{-(\mathrm{Ct}(\mathrm{GAPDH})}-\mathrm{Ct}$ (target gene)). 


\section{Statistical methods}

The unpaired two-sample Student's $t$-test was used for comparison of mean expression levels of indicated transcripts in samples in the TCGA dataset. For survival analysis, samples for which clinical follow-up was available $(n=58)$ were assigned into a low vs high brachyury group, based on an arbitrary cutoff of 240 for the overall brachyury reactivity index, set at the 75 th percentile for the overall population $(n=87)$. A KaplanMeier analysis was used to evaluate the association between brachyury expression and relapse-free survival. Cox proportional hazards regression model was used to adjust for potential confounding factors such as stage of disease and p53 expression. All statistical tests were two sided.

\section{Results}

\section{Brachyury mRNA expression in TNBC}

Samples $(n=1026)$ from the TCGA breast cancer database were subdivided according to the level of brachyury (T) mRNA expression into brachyury negative $(n=881)$, low $(n=72)$ or high $(n=73)$ groups, and subsequently analyzed for the level of expression of ER-, PR- and HER2 receptorencoding mRNAs. The most significant associations were observed with ER- $\alpha$ - and PR-encoding mRNAs
A

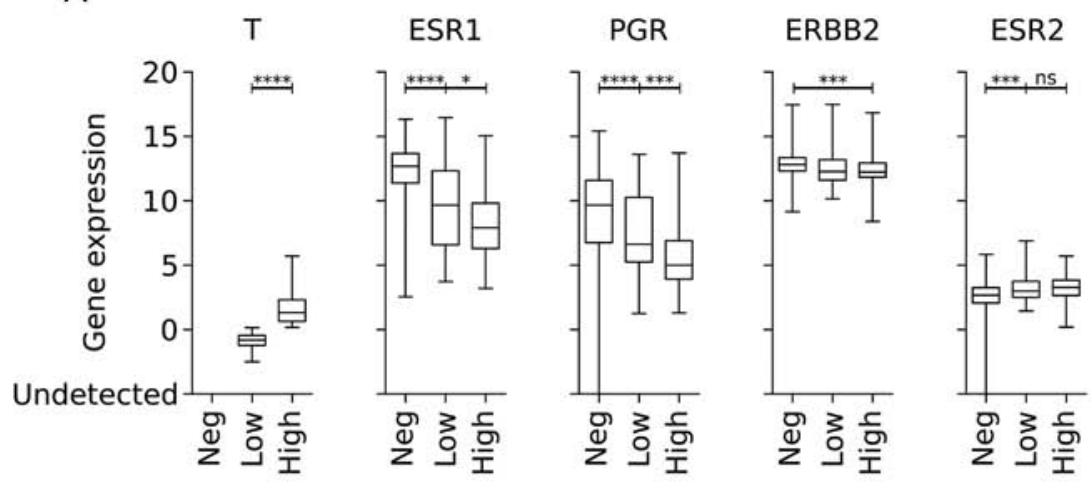

B

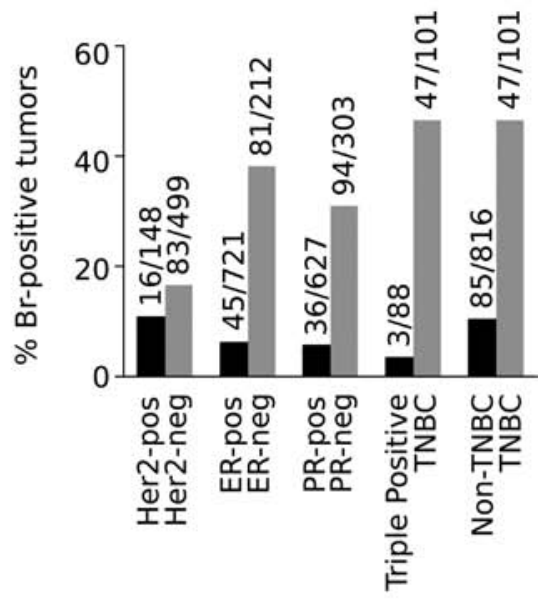

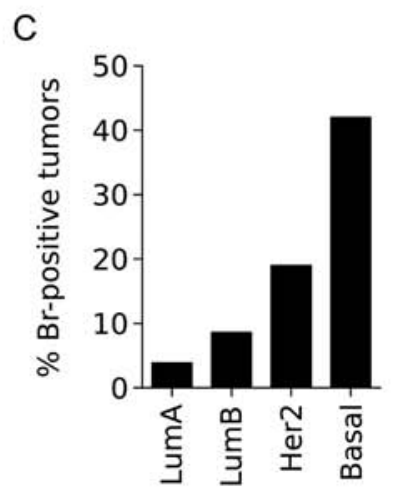

$\mathrm{D}$

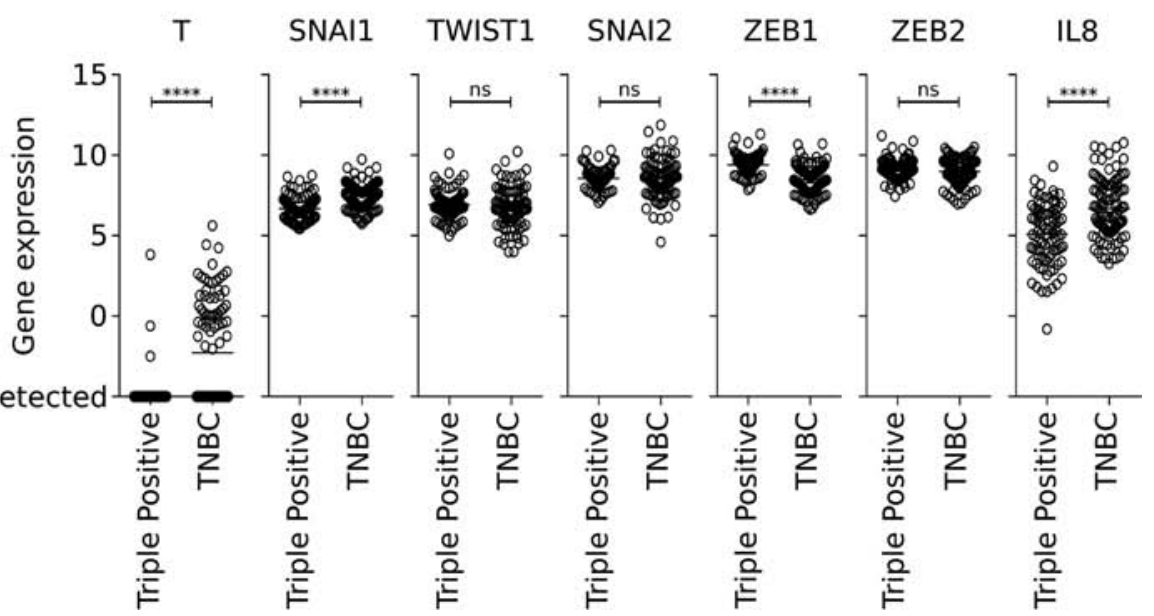

Figure 1

Brachyury mRNA upregulation in TNBC and basal breast cancers. (A) Analysis of expression of indicated transcripts in the breast cancer TCGA dataset, according to the level of brachyury (T) mRNA expression. Percent of tumors in the TCGA database that are positive for brachyury (T) mRNA expression in samples classified based on their hormone receptor expression (B) or according to the molecular classification (C). Analysis of expression of indicated transcripts in breast cancer samples of the TCGA database, classified as triple positive vs TNBC, in accordance with their expression of hormone receptors (D). Statistics were calculated using an unpaired $t$-test $\left({ }^{*} P<0.05 ; * * * P<0.001 ; * * * * P<0.0001 ;\right.$ ns, not significant). 
(ESR1 and PGR, respectively), which demonstrated a marked decrease of expression with increasing levels of brachyury (Fig. 1A). However, this reverse association was not seen in relation to HER2- or ER- $\beta$ encoding mRNAs (ERBB2 and ESR2, respectively, Fig. 1A). Further analysis of samples subdivided according to the HER2, ER and PR status demonstrated a predominant expression of brachyury mRNA among ER- vs ER+ (38 vs 6\%), PR- vs $\mathrm{PR}+(31$ vs $6 \%$ ), TNBC vs triple-positive (47 vs $3 \%$ ) or TNBC vs non-TNBC (47 vs $10 \%$ ) samples. In contrast to ER and PR, no difference was observed in the percentage of brachyury-positive tumors subdivided based on their HER2 expression (Fig. 1B). Brachyury mRNA expression was also evaluated in samples from the same dataset stratified based on the POM50 gene signature (Parker et al. 2009, Cancer Genome Atlas Network 2012). As shown in Fig. 1C, brachyury mRNA was detectable in 9 of 232 (3.9\%) luminal A, 11 of 128 (8.6\%) luminal B, 11 of 58 (19.0\%) HER2-enriched, and 40 of 95 (42.1\%) basal breast carcinoma samples.

In addition to brachyury, the TCGA dataset was used to interrogate the expression of various transcription factors known to induce EMT. Although brachyury (T) mRNA was predominantly expressed in TNBC (47 of 101) vs triple-positive ( 3 of 88 ) breast carcinoma samples, only a slight increase of SNAI1, a decrease of ZEB1 and no changes in the mRNA levels of TWIST1, SNAI2 or ZEB2 were observed in TNBC vs triple-positive breast tumors (Fig. 1D). Interestingly, we also noted a significant increase in IL8 mRNA levels in TNBC vs triplepositive breast tumors (Fig. 1E), a result in support of our previous studies demonstrating a positive association between brachyury and the IL8 axis in breast cancer (Fernando et al. 2011).
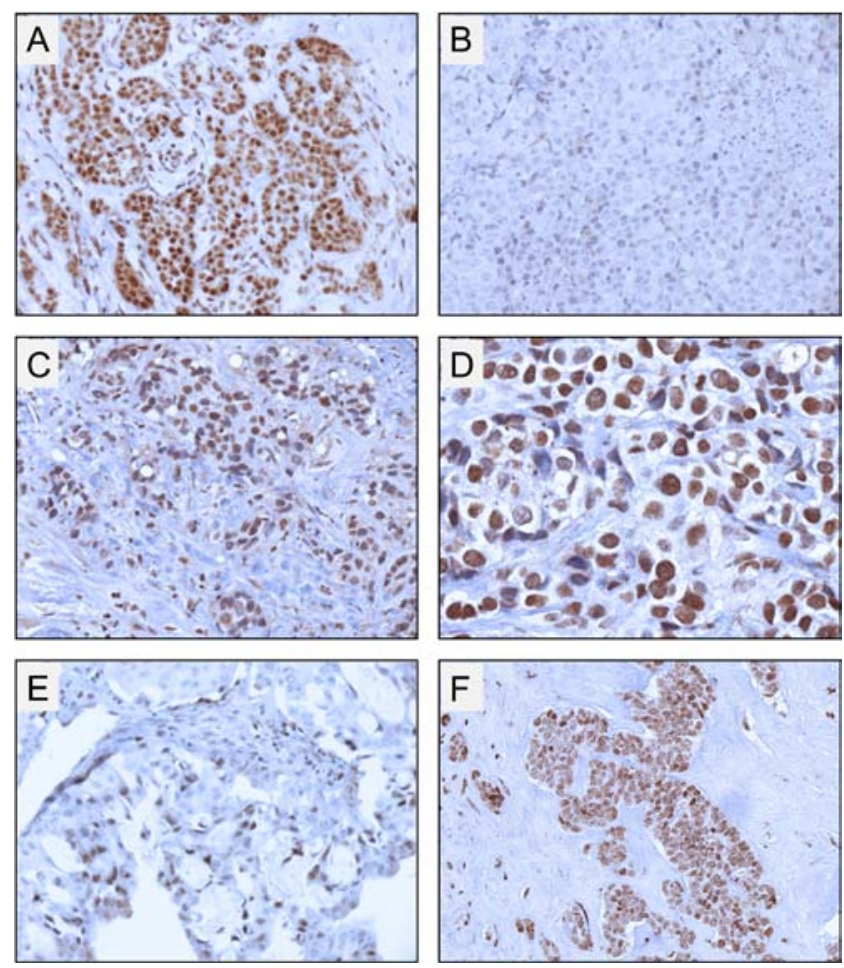

Figure 2

Immunohistochemical analysis of brachyury expression in primary and metastatic TNBC. Representative photomicrographs of brachyury staining on primary TNBC cases are reported on panels A and B. (A) Stage IIIB T2N3aM0 primary IDC (patient 71) showing positive nuclear and cytoplasmic staining in 80 and $40 \%$ of cancer cells, respectively. (B) Stage I T1CNOM0 primary IDC (patient 28 ) showing negative $(<5 \%)$ nuclear and cytoplasmic staining in cancer cells. (C) Pleural metastatic lesion (patient 84) showing positive nuclear and cytoplasmic staining in 80 and $20 \%$ of cancer cells, respectively. (D) Detail of brachyury staining at higher magnification (400X). (E) and (F) represent bone (patient 86) and lymph node (patient 78) metastasis with positive nuclear (60 and $100 \%$, respectively) and cytoplasmic (70 and $100 \%$, respectively) brachyury expression in cancer cells. Magnification: 200x (except panel D: 400x).

Table 3 Immunohistochemical detection of brachyury in biopsies obtained from metastatic lesions of TNBC patients.

\begin{tabular}{|c|c|c|c|c|c|c|c|c|c|c|c|c|}
\hline \multirow[b]{2}{*}{$\mathrm{Pt}$} & \multirow[b]{2}{*}{ Site } & \multirow[b]{2}{*}{ Ki67 } & \multirow[b]{2}{*}{ p53 } & \multicolumn{3}{|c|}{ Nuclear brachyury } & \multicolumn{3}{|c|}{ Cytoplasmic brachyury } & \multicolumn{3}{|c|}{ Total brachyury } \\
\hline & & & & Pos (\%) & SI & Index & Pos (\%) & $\mathrm{SI}$ & Index & Pos (\%) & SI & Index \\
\hline 78 & $\mathrm{LN}$ & 30 & NEG & 100 & +++ & 300 & 100 & + & 100 & 100 & +++ & 300 \\
\hline 79 & LN & 90 & NEG & 90 & +++ & 270 & 50 & + & 50 & 100 & +++ & 300 \\
\hline 80 & LN & 65 & POS & 80 & +++ & 240 & 0 & - & 0 & 80 & +++ & 240 \\
\hline 81 & $\mathrm{LN}$ & 50 & NEG & 70 & +++ & 210 & 50 & + & 50 & 80 & +++ & 240 \\
\hline 82 & LN & 70 & NEG & 80 & +++ & 240 & 0 & - & 0 & 80 & +++ & 240 \\
\hline 84 & Dist & 90 & NEG & 80 & +++ & 240 & 20 & + & 20 & 80 & +++ & 240 \\
\hline 86 & Dist & 60 & NEG & 60 & ++ & 120 & 70 & ++ & 140 & 80 & ++ & 160 \\
\hline 83 & Dist & 50 & NEG & 60 & +++ & 180 & 40 & ++ & 80 & 70 & +++ & 210 \\
\hline 87 & Dist & 10 & POS & 60 & +++ & 180 & 20 & + & 20 & 60 & +++ & 180 \\
\hline 85 & Dist & 80 & NEG & 30 & ++ & 60 & 20 & + & 20 & 40 & ++ & 80 \\
\hline
\end{tabular}

SI: staining intensity; NEG: negative; POS: positive. LN: lymph node; Dist: distant metastasis

http://erc.endocrinology-journals.org DOI: $10.1530 /$ ERC-16-0037
C 2016 Society for Endocrinology Printed in Great Britain 


\section{Brachyury protein in primary and metastatic TNBC}

Brachyury protein expression was assessed by IHC in 87 tumor tissues from patients diagnosed with TNBC by using a rabbit monoclonal anti-brachyury antibody (MAb 54-1) as described previously (Hamilton et al. 2015). Among 77 primary TNBC tumors, 71 of 77 (92\%) showed some level of brachyury expression in $>10 \%$ of the cancer cells, either in the nucleus or the cytoplasmic compartment (Table 2). As previously reported with other types of carcinomas, expression of brachyury was highly variable among primary tumors, with the percentage of brachyury-positive cells ranging from 10 to $100 \%$ and the intensity of staining varying between (+) and (+++). Representative images of two primary TNBC cases positive vs negative for brachyury expression are shown in Fig. $2 \mathrm{~A}$ and $\mathrm{B}$, respectively. In addition to primary tumors, brachyury expression was evaluated in metastatic lesions from 10 patients with TNBC (Table 3 and representative images in Fig. 2C-F). Brachyury was observed in $100 \%$ of metastasis cases, the majority of cases showing high-intensity staining for brachyury (+++) in $40-100 \%$ of the tumor cells.

Expression of brachyury was also evaluated in breast tissues adjacent and distant to the tumor. As shown in Fig. 3, a gradient of expression was observed with the highest degree of brachyury positivity detected in the tumor $>$ adjacent breast $>$ distant breast tissue. In the examples shown in Fig. 3A and D, the primary tumor overall nuclear and cytoplasmic brachyury staining ranged from 20 to $80 \%$ of the cancer cells, whereas expression in breast tissues adjacent vs distal to tumor corresponded to approximately 10\% (Fig. 3B and E) and $<5 \%$ (Fig. 3C and F) of the cells, respectively. Similarly, brachyury expression in the primary tumor shown in Fig. 3G corresponded to $80 \%$ of the cells, whereas expression in histologically normal breast tissue from the same patient demonstrated $<1 \%$ positivity for brachyury (Fig. $3 \mathrm{H}$ ). These results are in agreement with our previous study using a different antibrachyury monoclonal antibody (Palena et al. 2014b), in which brachyury-positive cells were observed in the breast tissue adjacent (15 of 27 cases) but not distal to the tumor, whereas no expression was detected in 14 benign breast tissues. The findings had an exception of two fibroadenoma cases in which focal expression of brachyury was observed. At present, it is unknown whether brachyury-expressing cells in the tissues adjacent to the tumor are cancer cells that have migrated toward the surrounding stroma or correspond to normal stromal cells that upregulated brachyury in response to tumorderived secreted factors.

In agreement with previous studies, brachyury protein was observed either in the nucleus and/or the cytosol of the TNBC cells. A comparative analysis of brachyury expression demonstrated a significant increase in nuclear brachyury protein levels, as detected by an increased reactivity index, in metastatic vs primary tumor samples $(P=0.02$, Fig. $4 \mathrm{~A})$, an association that was not observed with cytoplasmic brachyury. A similar association between nuclear localization of brachyury and clinical stage of disease was also observed, with samples from higher tumor stages (III-IV) having higher
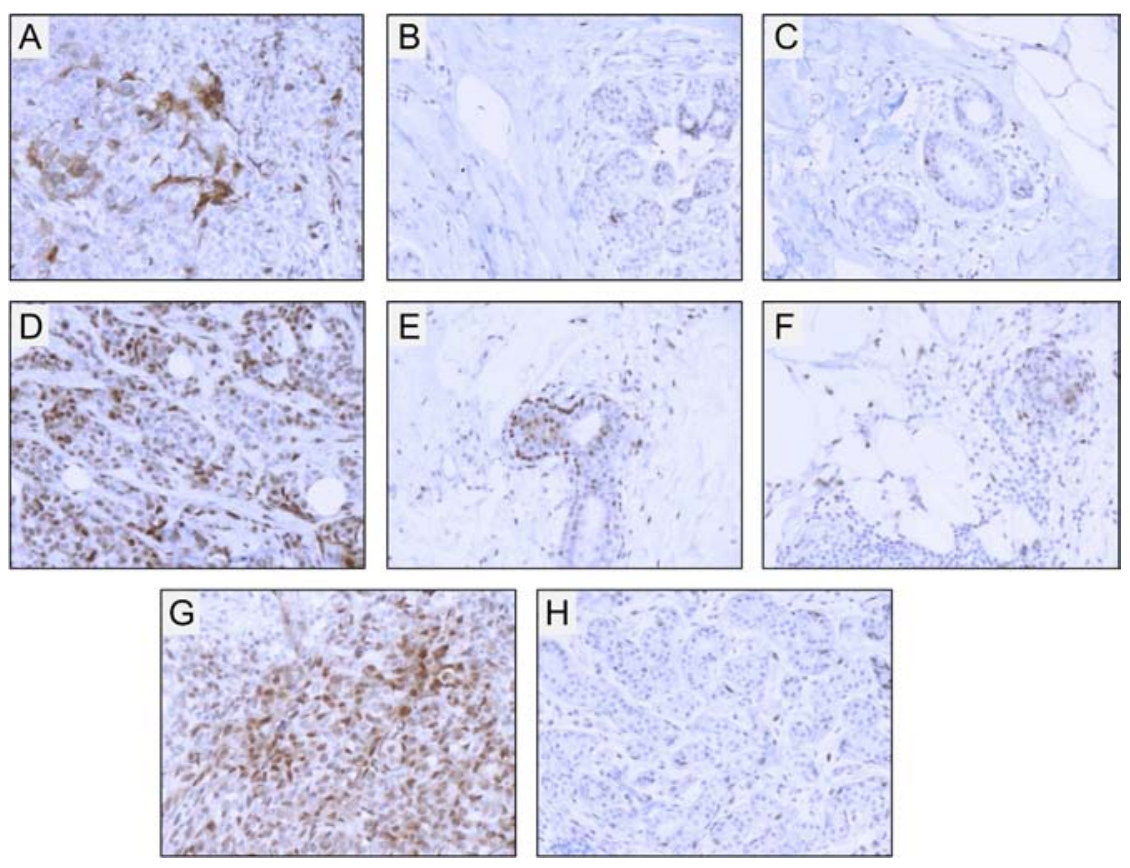

http://erc.endocrinology-journals.org DOI: 10.1530/ERC-16-0037

(C) 2016 Society for Endocrinology Printed in Great Britain

\section{Figure 3}

Immunohistochemical analysis of brachyury expression in primary TNBC and normal breast tissues adjacent or distant to the tumor. (A) Stage IIB T2N1aM0 primary tumor (patient 54) showing positive nuclear and cytoplasmic staining in 30 and $20 \%$ of cancer cells, respectively; (D) Stage IIA T2NOMO primary tumor (patient 37) showing nuclear and cytoplasmic staining in 70 and $80 \%$ of cancer cells, respectively. Panels (B) and (E) correspond to brachyury staining in breast tissues adjacent to the tumor. Panels $(C)$ and $(F)$ correspond to brachyury staining in breast tissues distant from the tumor. (G) Stage IIA T2N0M0 primary tumor (patient 30) showing both nuclear and cytoplasmic staining in $80 \%$ of cancer cells. (H) Brachyury staining in histologically normal breast tissue surrounding the tumor. Panel magnification: $200 \times$. 
A
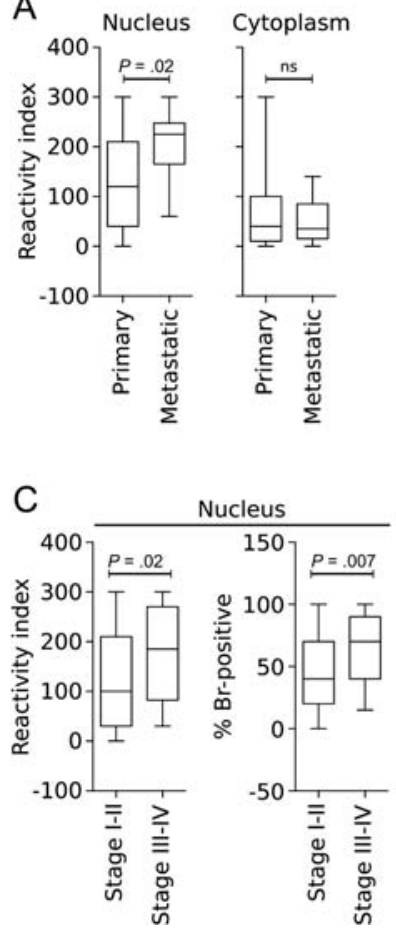

B

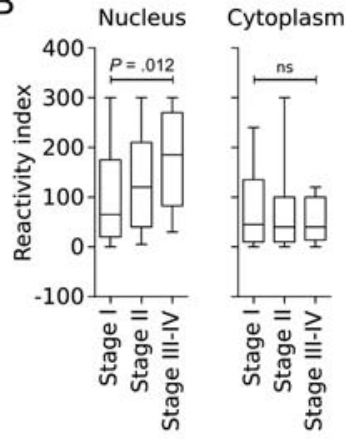

D

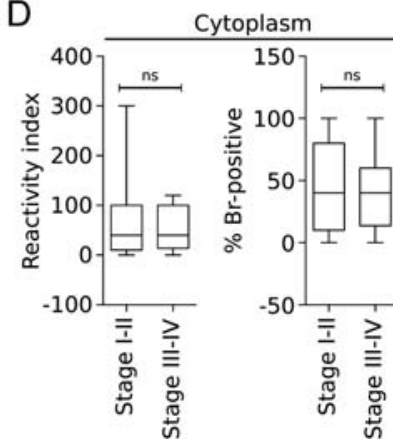

Figure 4

Prevalence of nuclear brachyury expression in metastatic and high-grade TNBC tumors. Brachyury reactivity index observed in the nucleus or the cytoplasm of primary vs metastatic (A) or TNBC samples according to stage (B, C and D). Samples were analyzed by IHC with an anti-brachyury monoclonal antibody. $P$ values were calculated using an unpaired $t$-test, with values for panel B representing a comparison between stage I and stages III-IV. (ns, not significant).

nuclear brachyury reactivity index $(P=0.012)$ than samples of stage I (Fig. 4B). The same difference was observed when combined samples from tumors stages I to II were compared with those of stages III-IV in which nuclear expression of brachyury was significantly



No. at risk

$\begin{array}{cccccc}\text { Low } & 41 & 35 & 20 & 8 & 1 \\ \text { High } & 17 & 9 & 5 & 0 & 0\end{array}$

\section{Figure 5}

Brachyury expression and prognosis. Kaplan-Meier estimates of recurrence-free survival in 58 cases of TNBC classified based on the brachyury expression level. The two groups (low vs high brachyury) were defined based on the overall brachyury reactivity index set at a cutoff of 240 , corresponding to the 75 th percentile of expression in the overall population $(n=87)$.

higher in tumors of advanced stages, both in terms of reactivity index $(P=0.02)$ and \% positive nuclei $(P=0.007$, Fig. 4C). This is a correlation that was not observed with cytoplasmic brachyury expression (Fig. 4D).

\section{Brachyury and TNBC prognosis}

To evaluate a potential association of brachyury expression in primary TNBC with prognosis, samples for which clinical follow-up was available $(n=58)$ were assigned into low vs high brachyury groups. It was

Table 4 Multivariate Cox proportional hazards regression analysis of the predictive value of clinical-pathological variables and brachyury expression on relapse-free survival of TNBC patients.

\begin{tabular}{|c|c|c|c|c|c|}
\hline \multirow[b]{2}{*}{ Variable } & \multirow[b]{2}{*}{$\mathbf{n}$} & \multicolumn{2}{|c|}{ Recurrence } & \multirow[b]{2}{*}{ HR $(\mathrm{Cl})$} & \multirow[b]{2}{*}{$P$ value } \\
\hline & & Yes & No & & \\
\hline \multicolumn{6}{|l|}{ Stage of disease } \\
\hline 1 & 21 & $2(10 \%)$ & $19(90 \%)$ & & \\
\hline II & 24 & $4(17 \%)$ & $20(83 \%)$ & & \\
\hline III & 13 & $4(31 \%)$ & $9(69 \%)$ & $1.83(0.60-5.57)$ & 0.285 \\
\hline \multicolumn{6}{|l|}{ p53 expression } \\
\hline Negative & 26 & $4(15 \%)$ & $22(85 \%)$ & & \\
\hline Positive & 32 & $6(19 \%)$ & $26(81 \%)$ & $1.34(0.30-5.91)$ & 0.699 \\
\hline \multicolumn{6}{|c|}{ Brachyury expressiona } \\
\hline Negative $(<240)$ & 41 & $5(12 \%)$ & $36(88 \%)$ & & \\
\hline Positive $(\geq 240)$ & 17 & $5(29 \%)$ & $12(71 \%)$ & $3.92(1.02-15.1)$ & 0.047 \\
\hline
\end{tabular}

aCategorized according to an arbitrary cutoff calculated as the 75th percentile of brachyury reactivity index for total brachyury staining in the overall population $(n=87)$. 
done based on an arbitrary cutoff of 240 for the overall brachyury reactivity index, set at the 75 th percentile for the overall population $(n=87)$. A Kaplan-Meier estimate of survival showed that high brachyury expression in the primary tumor is significantly associated with decreased survival ( $P=0.03, n=58$, long-rank test $=2.17$, Fig. 5$)$. To minimize the effect of clinical-pathological variables that might cause false-positive association between brachyury and poor prognosis, a multivariate Cox proportional hazards regression survival analysis was conducted. It was found that high brachyury expression (reactivity index $\geq 240$ ) significantly associates with low relapse-free survival $(P=0.047, n=58, \mathrm{COXPH,} \mathrm{HR}=3.92$, $\mathrm{CI}=1.02-15.1$ ), compared with the low brachyury expression group (Table 4 ).

\section{Brachyury expression in TNBC cell lines}

Immunofluorescent staining of mesenchymal vimentin and epithelial ZO1 proteins was used for phenotypic confirmation of a panel of TNBC (MDA-MB-231, MDA-MB-436 and Hs578T) and non-TNBC (BT-474, ZR-75-1 and MCF7) human breast carcinoma lines. As expected, strong expression of mesenchymal vimentin and little expression of epithelial ZO1 were observed with TNBC cells, whereas non-TNBC cells showed high amounts of ZO1 in the absence of vimentin expression (Fig. 6A). When expression of brachyury mRNA was evaluated in each cell line, higher levels were observed in TNBC vs non-TNBC cells (Fig. 6B). The potential role of brachyury in tumor EMT was also investigated with MDA-MB-436

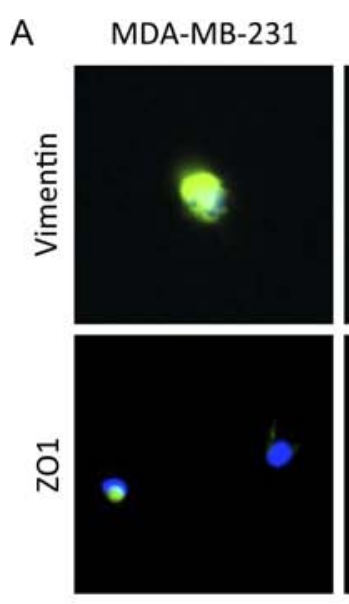

B

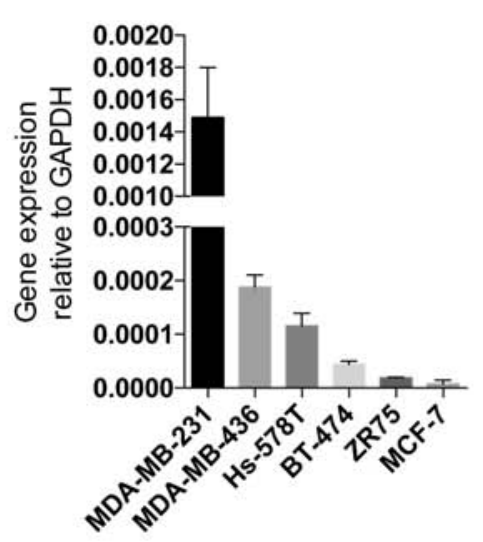

Hs $578 \mathrm{~T}$
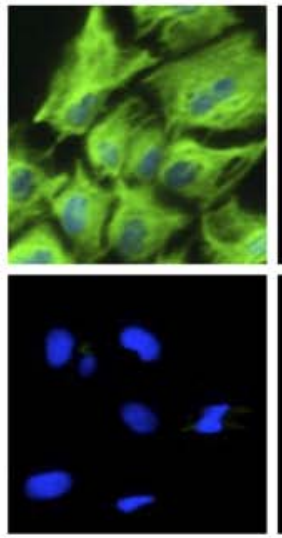

C
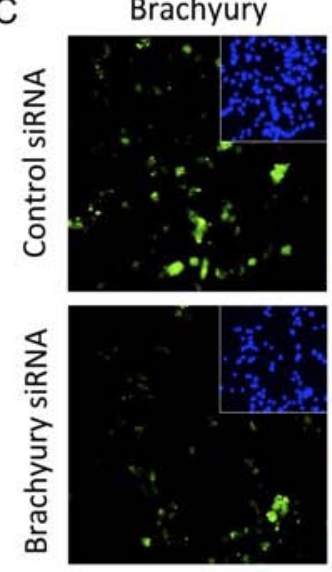

BT-474
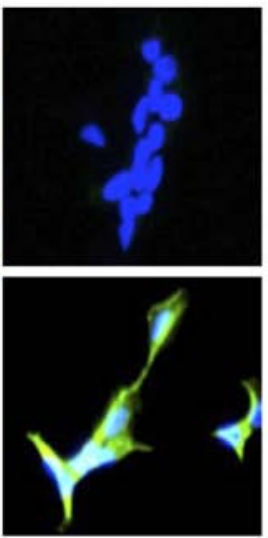

Vimentin
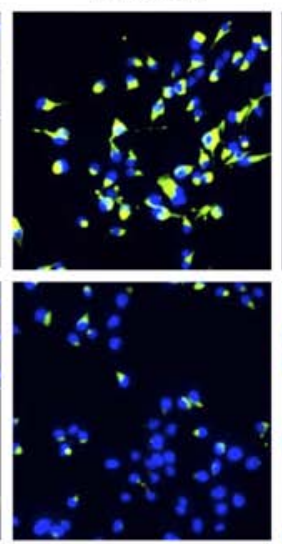

ZR-75-1
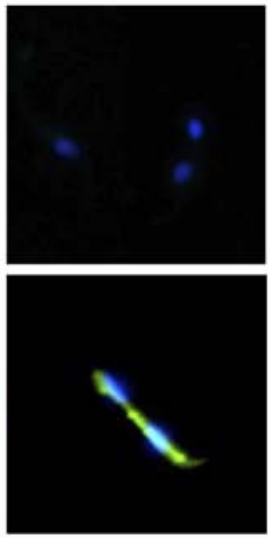

Fibronectin
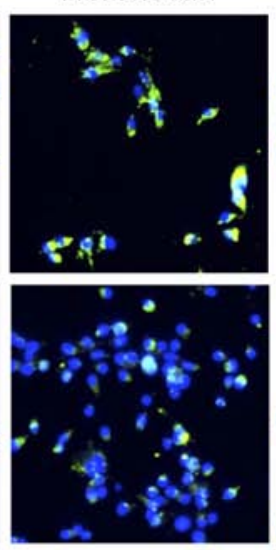

MCF7
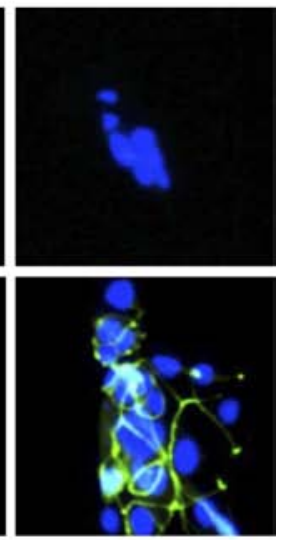

Z01
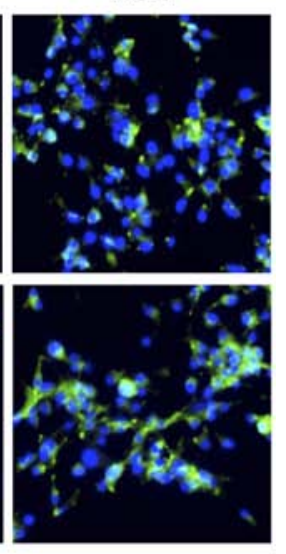

MDA-MB-436 cells

Figure 6

Brachyury associates with mesenchymal features in human TNBC cell lines. (A) Immunofluorescent detection of vimentin and ZO1 (green signal) in a panel of TNBC and non-TNBC cell lines. (B) Relative brachyury mRNA expression levels in the various cell lines. Error bars indicate the standard error of the mean of triplicate measurements. (C) Silencing brachyury expression in MDA-MB-436 cells is associated with a reduction in the expression of mesenchymal markers vimentin and fibronectin and increased expression of the epithelial marker ZO1 (green signal). Blue signal corresponds to DAPI staining of nuclei.

http://erc.endocrinology-journals.org DOI: 10.1530/ERC-16-0037
(C) 2016 Society for Endocrinology Printed in Great Britain
Published by Bioscientifica Ltd. 
cells, in which silencing of brachyury resulted in reduced expression of vimentin and fibronectin and increased expression of epithelial ZO1 (Fig. 6C). These observations thus suggested that brachyury not only associates with but is also required to maintain a mesenchymal-like phenotype in the MDA-MB-436 triple-negative breast cancer cell line.

\section{Discussion}

Elucidation of novel, potential therapeutic targets for the treatment of TNBC remains an urgent need in the absence of current, effective treatment for this aggressive tumor type. Our group and others have previously described the selective expression of the transcription factor brachyury, an immunotherapy target and a driver of tumor EMT (Palena et al. 2007, Fernando et al. 2010, Hamilton et al. 2013, Palena et al. 2014a, Palena \& Hamilton 2015), in primary and metastatic lesions of invasive ductal carcinomas of the breast (Palena et al. 2014b, Shao et al. 2015). In this study, we further expanded those previous observations and demonstrated for the first time a prevalent expression of brachyury mRNA and protein in TNBC compared with other breast cancer subtypes. Variable levels of brachyury protein were observed by IHC in approximately $90 \%$ of primary and $100 \%$ of metastatic TNBC lesions analyzed. However, expression of brachyury was highly variable among primary tumors, with the percentage of positive cells ranging from 10 to $100 \%$ and the intensity of staining varying between $(+)$ and $(+++)$. Based on the relevant role of brachyury in tumor dissemination and/or resistance to anticancer treatments, it is expected that a small fraction of brachyury-positive cells in a tumor mass could have a major impact in terms of clinical outcome. With this functional relevance of brachyury in mind, a tissue has been designated here as 'brachyury positive' if at least $10 \%$ of the cancer cells exhibited some level of staining.

It is important to point out that in addition to providing evidence of variable levels of brachyury expression in TNBC, the data presented here also indicate that some level of brachyury could be present in normal breast tissues adjacent or distal to the tumor. These results contrast with our previous observations, in which brachyury was not detected in normal breast tissues from patients with benign conditions (Palena et al. 2014b). Two recently completed phase I clinical trials of a yeastbrachyury vaccine (Heery etal. 2015b) or a MVA-brachyuryTRICOM vaccine (Heery et al. 2015a) demonstrated no evidence of any autoimmune occurrence in the presence of measurable brachyury-specific CD4+ and CD8+ T-cell responses, even in normal testis and thyroid tissues that were previously shown to express some level of the brachyury protein. However, the presence of brachyury in normal breast tissues surrounding TNBC raises concern that an autoimmune event against those tissues could take place in vaccinated patients. This warrants careful evaluation in future studies of brachyury-based vaccines.

Three cancer vaccine platforms against brachyury have been developed and two are currently undergoing phase I/II clinical evaluation (Hamilton et al. 2013, Gabitzsch et al. 2015, Heery et al. 2015a,b). In phase I clinical studies, brachyury-based vaccines have demonstrated the ability to elicit CD8+ and CD4+ brachyury-specific T-cell immune responses in the blood of patients after vaccination. These brachyury-specific T cells are shown to produce IFN $\gamma$, IL2 and TNF $\alpha$ and/or to express CD107a, a marker of lytic potential. Although some evidence of clinical response was observed, the small number of patients evaluated precluded the analysis of any potential association between the degree of antigen-specific immune response and clinical outcome. Further studies with larger number of patients need to be conducted to investigate whether such association could be established. In a previous report, we have shown that brachyury-specific $\mathrm{T}$ cells generated from the blood of cancer patients can lyse basal MDA-MB-231 cancer cells in an MHC-restricted manner (Palena et al. 2014b). Those experiments were conducted with unfractionated CD8+ T cells, and it is expected that a higher degree of lysis would be observed with tetramerisolated, brachyury-specific $\mathrm{T}$ cells.

Although the molecular classification of breast cancer into various subtypes has revealed a high degree of heterogeneity in this disease, the majority of TNBC cases (56-95\%) can be molecularly categorized as basallike (Prat et al. 2012). Tumors of this subtype are defined by the expression of genes typically present in normal breast basal/myoepithelial cells and are characterized by a high proliferation index, p53 mutations and an aggressive course with frequent tumor relapse (Reis-Filho \& Tutt 2008). The phenomenon of EMT, a phenotypic switch that allows epithelial cells to acquire motility, invasiveness and resistance to cell death while exhibiting features characteristic of mesenchymal cells, is being postulated as a relevant mechanism that fosters progression toward metastatic disease (Kalluri \& Weinberg 2009). In agreement, it is the aggressive basal-like group of breast cancer that commonly exhibits mesenchymal features, 
including expression of vimentin, smooth-muscle-actin (SMA) and N-cadherin in place of epithelial E-cadherin (Blick et al. 2008, Sarrio et al. 2008).

The transcription factor brachyury has been previously shown to induce phenotypic changes in carcinoma cells reminiscent of an EMT, a phenomenon associated with tumor dissemination, metastasis and acquisition of resistance to a variety of antitumor therapies (Huang et al. 2013, Larocca et al. 2013). In this regard, we and others have shown that the presence of high levels of brachyury in the primary tumor can predict poor prognosis in a range of human carcinomas including lung (Haro et al. 2013), hepatocellular (Du et al. 2014), GIST (Pinto et al. 2015), prostate (Pinto et al. 2014), colorectal (Kilic et al. 2011, Sarkar et al. 2012) and hormone receptor-positive breast cancer (Palena et al. 2014b). In agreement, here we have observed that high levels of brachyury in primary TNBC tumors associate with poor survival. However, it is important to point out that studies of the association between brachyury and patient survival were based on an arbitrary cutoff of $\geq 240$ for the brachyury reactivity index. Thus, expression of brachyury in primary TNBC is proposed to be a bad prognostic indicator only for the fraction of tumors that express brachyury in at least $80 \%$ of the cancer cells and at high staining intensity (+++), which will result in reactivity index values $\geq 240$.

In our previous studies, we have conducted gain- and loss-of-function experiments to investigate the particular role of brachyury in breast carcinoma cells. Using basallike, hormone-receptor-negative MDA-MB-436 cells, we have shown that silencing of brachyury is able to significantly reduce cell invasiveness and the tumor cells' ability to form mammospheres in primary and secondary cultures, a measure of tumor stemness, relative to their control counterparts. The loss of brachyury was also shown to significantly sensitize basal-like MDA-MB-436 cells to the cytotoxic activity of docetaxel, thus demonstrating a potential role for brachyury in tumor invasiveness and resistance to cell death in TNBC (Palena et al. 2014b). A recent report (Ben-Hamo et al. 2014) has identified brachyury as a dominant gene in a network of genes that most significantly discriminate TNBC from non-TNBC samples. Here, we have further demonstrated the prevalent expression of brachyury in a panel of TNBC human breast carcinoma cell lines and validated its role as a driver of tumor EMT with MDA-MB-436 TNBC cells, in which brachyury silencing markedly reduced the expression of mesenchymal vimentin and fibronectin, whereas increased the expression of epithelial ZO1.
In this study, the expression of brachyury mRNA was shown to be predominant among TNBC vs triple-positive samples in the TCGA database, whereas that was not the case with other EMT drivers, including TWIST1, SNAI2 or ZEB2 mRNA. These results seemed to contradict the expected enrichment of EMT markers in TNBC samples. Although the reason for these observations is unknown at this time, we have previously observed that expression of TWIST1, SNAI1 and SNAI2 mRNA is detectable in normal tissues at levels comparable with those observed in tumors (Roselli et al. 2012, Palena et al. 2014b). As the mRNA analysis includes not only tumor cells but also surrounding normal tissues, one possible explanation for the absence of difference of expression of the EMT markers between different tumor types could be the simultaneous detection in adjacent normal cells. Unlike TWIST1, SNAI1 and SNAI2, we have previously shown that expression of brachyury mRNA is undetectable in normal breast tissues (Palena et al. 2014b).

Among genes that were differentially expressed between TNBC and other tumors was IL8, a chemokine that was previously associated with tumor stemness and EMT in breast cancer (Ginestier et al. 2010, Fernando et al. 2011, Palena et al. 2012). We have previously demonstrated that IL8 is able to significantly upregulate brachyury expression in breast cancer cells at the transcriptional level and that upregulation of brachyury leads to increased secretion of IL8 and overexpression of IL8 receptors. It thus establishes an autocrine feedforward loop that sustains the mesenchymal, resistant phenotype. We hypothesize that the presence of this autocrine regulatory loop in TNBC could drive the expression of brachyury and, potentially, the acquisition of mesenchymal and stem-like features by the tumor cells.

Although there have been some discrepancies regarding the detection of brachyury protein in various types of carcinomas, we believe that these inconsistencies are due to the utilization of various antibodies possessing a range of affinity and specificity for the target protein brachyury. We and others have shown that brachyury can be detected in the nucleus and/or the cytosol of carcinoma cells, whereas its expression in chordomas is predominantly seen in the nucleus of the tumor cells (Pinto et al. 2014, Hamilton et al. 2015, Miettinen et al. 2015). In agreement with those previous observations, here we demonstrated that brachyury protein can be detected either in the nucleus and/or the cytosol of TNBC cells, although their expression is somehow linked with a positive correlative trend observed between the nuclear

Published by Bioscientifica Ltd 
and cytoplasmic reactivity index $(r=0.236, P=0.04)$. Although the biological relevance of nuclear vs cytosolic brachyury localization in tumor cells remains unknown, it was interesting to observe in this study that nuclear (but not cytosolic) expression of brachyury is associated with clinical stage of disease and was more predominant in metastatic vs primary tumor tissues. This potentially indicates a role for brachyury in tumor progression when localized in the nucleus, where its transcriptional activity is expected to take place. Future studies are warranted to evaluate, in a larger cohort of TNBC patients, the potential association between nuclear vs cytoplasmic brachyury expression and clinical outcome.

Altogether our observations demonstrate the potential of brachyury as a target for the treatment of early or metastatic TNBC and provide rationale for using a brachyury-targeting vaccine approach for treatment of this disease.

\section{Declaration of interest}

The authors declare that there is no conflict of interest that could be perceived as prejudicing the impartiality of the research reported.

\section{Funding}

This research was supported by the Intramural Research Program of the Center for Cancer Research, National Cancer Institute, National Institutes of Health and by research funding from the European Social Fund, under the Italian Ministry of Education, University and Research PON03PE_00146_1/10 BIBIOFAR (CUP B88F12000730005) to F G.

\section{Author's contribution statement}

D H H and C P carried out studies at the mRNA level, performed cell linebased assays data analysis and wrote the manuscript. M R, P F, L C, F C, M T and $F$ G carried out the immunohistochemical analyses, performed data analysis and wrote the manuscript. $\mathrm{CP}$ and $\mathrm{F} \mathrm{G}$ designed and supervised the study. All authors read and approved the final manuscript. D H Hamilton, M Roselli, C Palena and F Guadagni contributed equally to this work.

\section{Acknowledgements}

The authors would like to thank Dr Jeffrey Schlom from the National Cancer Institute, $\mathrm{NIH}$, for his invaluable input along the study. Some of the results published here are based on data from the TCGA Research Network.

\section{References}

Ben-Hamo R, Gidoni M \& Efroni S 2014 PhenoNet: identification of key networks associated with disease phenotype. Bioinformatics $\mathbf{3 0}$ 2399-2405. (doi:10.1093/bioinformatics/btu199)

Blick T, Widodo E, Hugo H, Waltham M, Lenburg ME, Neve RM \& Thompson EW 2008 Epithelial mesenchymal transition traits in human breast cancer cell lines. Clinical and Experimental Metastasis 25 629-642. (doi:10.1007/s10585-008-9170-6)

Cancer Genome Atlas Network 2012 Comprehensive molecular portraits of human breast tumours. Nature 490 61-70. (doi:10.1038/nature11412)

Carey LA, Perou CM, Livasy CA, Dressler LG, Cowan D, Conway K, Karaca G, Troester MA, Tse CK, Edmiston S, et al. 2006 Race, breast cancer subtypes, and survival in the Carolina Breast Cancer Study. JAMA 295 2492-2502. (doi:10.1001/jama.295.21.2492)

Creighton CJ, Li X, Landis M, Dixon JM, Neumeister VM, Sjolund A, Rimm DL, Wong H, Rodriguez A, Herschkowitz JI, et al. 2009 Residual breast cancers after conventional therapy display mesenchymal as well as tumor-initiating features. PNAS $\mathbf{1 0 6}$ 13820-13825. (doi:10.1073/pnas.0905718106)

David JM, Hamilton DH \& Palena C 2016 MUC1 upregulation promotes immune resistance in tumor cells undergoing brachyury-mediated epithelial-mesenchymal transition. Oncoimmunology 5 e1117738. (doi:10.1080/2162402X.2015.1117738)

Dent R, Trudeau M, Pritchard KI, Hanna WM, Kahn HK, Sawka CA, Lickley LA, Rawlinson E, Sun P \& Narod SA 2007 Triple-negative breast cancer: clinical features and patterns of recurrence. Clinical Cancer Research 13 4429-4434. (doi:10.1158/1078-0432.CCR-063045)

Du R, Wu S, Lv X, Fang H, Wu S \& Kang J 2014 Overexpression of brachyury contributes to tumor metastasis by inducing epithelialmesenchymal transition in hepatocellular carcinoma. Journal of Experimental and Clinical Cancer Research 33 105. (doi:10.1186/ s13046-014-0105-6)

Fernando RI, Litzinger M, Trono P, Hamilton DH, Schlom J \& Palena C 2010 The T-box transcription factor Brachyury promotes epithelialmesenchymal transition in human tumor cells. Journal of Clinical Investigation 120 533-544. (doi:10.1172/JCI38379)

Fernando RI, Castillo MD, Litzinger M, Hamilton DH \& Palena C 2011 IL-8 signaling plays a critical role in the epithelial-mesenchymal transition of human carcinoma cells. Cancer Research 71 5296-5306. (doi:10.1158/0008-5472.CAN-11-0156)

Fernando RI, Hamilton DH, Dominguez C, David JM, McCampbell KK \& Palena C 2016 IL-8 signaling is involved in resistance of lung carcinoma cells to erlotinib. Oncotarget 7 42031-42044. (doi:10.18632/oncotarget.9662)

Gabitzsch ES, Tsang KY, Palena C, David JM, Fantini M, Kwilas A, Rice AE, Latchman Y, Hodge JW, Gulley JL, et al. 2015 The generation and analyses of a novel combination of recombinant adenovirus vaccines targeting three tumor antigens as an immunotherapeutic. Oncotarget 6 31344-31359. (doi:10.18632/ oncotarget.5181)

Ginestier C, Liu S, Diebel ME, Korkaya H, Luo M, Brown M, Wicinski J, Cabaud O, Charafe-Jauffret E, Birnbaum D, et al. 2010 CXCR1 blockade selectively targets human breast cancer stem cells in vitro and in xenografts. Journal of Clinical Investigation 120 485-497. (doi:10.1172/JCI39397)

Gupta GP \& Massague J 2006 Cancer metastasis: building a framework. Cell 127 679-695. (doi:10.1016/j.cell.2006.11.001)

Haffty BG, Yang Q, Reiss M, Kearney T, Higgins SA, Weidhaas J, Harris L, Hait W \& Toppmeyer D 2006 Locoregional relapse and distant metastasis in conservatively managed triple negative early-stage breast cancer. Journal of Clinical Oncology 24 5652-5657. (doi:10.1200/JCO.2006.06.5664)

Hamilton DH, Litzinger MT, Jales A, Huang B, Fernando RI, Hodge JW, Ardiani A, Apelian D, Schlom J \& Palena C 2013 Immunological targeting of tumor cells undergoing an epithelial-mesenchymal transition via a recombinant brachyury-yeast vaccine. Oncotarget 4 1777-1790. (doi:10.18632/oncotarget.1295)

Hamilton DH, Huang B, Fernando RI, Tsang KY \& Palena C 2014 WEE1 inhibition alleviates resistance to immune attack of tumor cells undergoing epithelial-mesenchymal transition. Cancer Research $\mathbf{7 4}$ 2510-2519. (doi:10.1158/0008-5472.CAN-13-1894) 
Hamilton DH, Fernando RI, Schlom J \& Palena C 2015 Aberrant expression of the embryonic transcription factor brachyury in human tumors detected with a novel rabbit monoclonal antibody. Oncotarget 6 4853-4862. (doi:10.18632/oncotarget.3086)

Haro A, Yano T, Kohno M, Yoshida T, Koga T, Okamoto T, Takenoyama M \& Maehara Y 2013 Expression of Brachyury gene is a significant prognostic factor for primary lung carcinoma. Annals of Surgical Oncology 20 (Supplement 3) S509-S516. (doi:10.1245/s10434013-2914-9)

Heery CR, Donahue R, Lepone L, Grenga I, Richards J, Metenou S, Fernando RI, Dirmeier U, Singh H, Madan R, et al. 2015a Phase I, doseescalation, clinical trial of MVA-Brachyury-TRICOM vaccine demonstrating safety and brachyury-specific T cell responses. Journal for ImmunoTherapy of Cancer 3 1-2. (doi:10.1186/2051-1426-3-s2-p132)

Heery CR, Singh BH, Rauckhorst M, Marte JL, Donahue RN, Grenga I, Rodell TC, Dahut W, Arlen PM, Madan RA, et al. 2015b Phase I trial of a Yeast-based therapeutic cancer vaccine (GI-6301) targeting the transcription factor Brachyury. Cancer Immunology Research 3 1248-1256. (doi:10.1158/2326-6066.CIR-15-0119)

Huang B, Cohen JR, Fernando RI, Hamilton DH, Litzinger MT, Hodge JW \& Palena C 2013 The embryonic transcription factor Brachyury blocks cell cycle progression and mediates tumor resistance to conventional antitumor therapies. Cell Death Disease 4 e682. (doi:10.1038/cddis.2013.208)

Jeong H, Ryu YJ, An J, Lee Y \& Kim A 2012 Epithelial-mesenchymal transition in breast cancer correlates with high histological grade and triple-negative phenotype. Histopathology 60 E87-95. (doi:10.1111/j.1365-2559.2012.04195.x)

Kalluri R \& Weinberg RA 2009 The basics of epithelial-mesenchymal transition. Journal of Clinical Investigation 119 1420-1428. (doi:10.1172/JCI39104)

Kilic N, Feldhaus S, Kilic E, Tennstedt P, Wicklein D, Wasielewski R, Viebahn C, Kreipe H \& Schumacher U 2011 Brachyury expression predicts poor prognosis at early stages of colorectal cancer. European Journal of Cancer 47 1080-1085. (doi:10.1016/j.ejca.2010.11.015)

Kispert A, Koschorz B \& Herrmann BG 1995 The T protein encoded by Brachyury is a tissue-specific transcription factor. EMBO Journal 14 4763-4772.

Larocca C, Cohen JR, Fernando RI, Huang B, Hamilton DH \& Palena C 2013 An autocrine loop between TGF-beta1 and the transcription factor brachyury controls the transition of human carcinoma cells into a mesenchymal phenotype. Molecular Cancer Therapy 12 1805-1815. (doi:10.1158/1535-7163.MCT-12-1007)

Metzger-Filho O, Tutt A, de Azambuja E, Saini KS, Viale G, Loi S, Bradbury I, Bliss JM, Azim HA Jr, Ellis P, et al. 2012 Dissecting the heterogeneity of triple-negative breast cancer. Journal of Clinical Oncology 30 1879-1887. (doi:10.1200/JCO.2011.38.2010)

Miettinen M, Wang Z, Lasota J, Heery C, Schlom J \& Palena C 2015 Nuclear brachyury expression is consistent in chordoma, common in germ cell tumors and small cell carcinomas, and rare in other carcinomas and sarcomas: an immunohistochemical study of 5229 Cases. American Journal of Surgical Pathology 39 1305-1312. (doi:10.1097/PAS.0000000000000462)

O'Brien KM, Cole SR, Tse CK, Perou CM, Carey LA, Foulkes WD, Dressler LG, Geradts J \& Millikan RC 2010 Intrinsic breast tumor subtypes, race, and long-term survival in the Carolina Breast Cancer Study. Clinical Cancer Research 16 6100-6110. (doi:10.1158/10780432.ccr-10-1533)

Palena C \& Hamilton DH 2015 Immune targeting of tumor epithelialmesenchymal transition via brachyury-based vaccines. Advances in Cancer Research 128 69-93. (doi:10.1016/bs.acr.2015.04.001)

Palena C, Polev DE, Tsang KY, Fernando RI, Litzinger M, Krukovskaya LL, Baranova AV, Kozlov AP \& Schlom J 2007
The human T-box mesodermal transcription factor Brachyury is a candidate target for T-cell-mediated cancer immunotherapy. Clinical Cancer Research 13 2471-2478. (doi:10.1158/1078-0432. CCR-06-2353)

Palena C, Hamilton DH \& Fernando RI 2012 Influence of IL-8 on the epithelial-mesenchymal transition and the tumor microenvironment. Future Oncology 8 713-722. (doi:10.2217/ fon.12.59)

Palena C, Fernando RI \& Hamilton DH 2014a An immunotherapeutic intervention against tumor progression: targeting a driver of the epithelial-to-mesenchymal transition. Oncoimmunology 3 e27220. (doi:10.4161/onci.27220)

Palena C, Roselli M, Litzinger MT, Ferroni P, Costarelli L, Spila A, Cavaliere F, Huang B, Fernando RI, Hamilton DH, et al. $2014 b$ Overexpression of the EMT driver brachyury in breast carcinomas: association with poor prognosis. Journal of the National Cancer Institute 106 dju054. (doi:10.1093/jnci/dju054)

Parker JS, Mullins M, Cheang MC, Leung S, Voduc D, Vickery T, Davies S, Fauron C, He X, Hu Z, et al. 2009 Supervised risk predictor of breast cancer based on intrinsic subtypes. Journal of Clinical Oncology 27 1160-1167. (doi:10.1200/JCO.2008.18.1370)

Perou CM, Sorlie T, Eisen MB, van de Rijn M, Jeffrey SS, Rees CA, Pollack JR, Ross DT, Johnsen H, Akslen LA, et al. 2000 Molecular portraits of human breast tumours. Nature 406 747-752. (doi:10.1038/35021093)

Pinto F, Pertega-Gomes N, Pereira MS, Vizcaino JR, Monteiro P, Henrique RM, Baltazar F, Andrade RP \& Reis RM 2014 T-box transcription factor brachyury is associated with prostate cancer progression and aggressiveness. Clinical Cancer Research 20 4949-4961. (doi:10.1158/1078-0432.CCR-14-0421)

Pinto F, Campanella NC, Abrahao-Machado LF, Scapulatempo-Neto C, de Oliveira AT, Brito MJ, Andrade RP, Guimaraes DP \& Reis RM 2015 The embryonic Brachyury transcription factor is a novel biomarker of GIST aggressiveness and poor survival. Gastric Cancer 19 651-659. (doi:10.1007/s10120-015-0505-0)

Prat A, Parker JS, Fan C \& Perou CM 2012 PAM50 assay and the threegene model for identifying the major and clinically relevant molecular subtypes of breast cancer. Breast Cancer Research Treatment 135 301-306. (doi:10.1007/s10549-012-2143-0)

Reis-Filho JS \& Tutt AN 2008 Triple negative tumours: a critical review. Histopathology 52 108-118. (doi:10.1111/j.1365-2559.2007.02889.x)

Roselli M, Fernando RI, Guadagni F, Spila A, Alessandroni J, Palmirotta R, Costarelli L, Litzinger M, Hamilton DH, Huang B, et al. 2012 Brachyury, a driver of the epithelial-mesenchymal transition, is overexpressed in human lung tumors: an opportunity for novel interventions against lung cancer. Clinical Cancer Research 18 3868-3879. (doi:10.1158/1078-0432.CCR-11-3211)

Sarkar D, Shields B, Davies ML, Muller J \& Wakeman JA 2012 BRACHYURY confers cancer stem cell characteristics on colorectal cancer cells. International Journal of Cancer 30 328-337. (doi:10.1002/ ijc.26029)

Sarrio D, Rodriguez-Pinilla SM, Hardisson D, Cano A, Moreno-Bueno G \& Palacios J 2008 Epithelial-mesenchymal transition in breast cancer relates to the basal-like phenotype. Cancer Research 68 989-997. (doi:10.1158/0008-5472.CAN-07-2017)

Shao C, Zhang J, Fu J \& Ling F 2015 The potential role of Brachyury in inducing epithelial-to-mesenchymal transition (EMT) and HIF1alpha expression in breast cancer cells. Biochemical and Biophysical Research Communications 467 1083-1089. (doi:10.1016/j. bbrc.2015.09.076)

Thiery JP \& Sleeman JP 2006 Complex networks orchestrate epithelialmesenchymal transitions. Nature Review Molecular Cell Biology 7 131-142. (doi:10.1038/nrm1835)

Received in final form 5 August 2016

Accepted 9 August 2016

Published by Bioscientifica Ltc. http://erc.endocrinology-journals.org

DOI: $10.1530 /$ ERC-16-0037
๑ 2016 Society for Endocrinology Printed in Great Britain 